\title{
Does a Paradox Exist in Child Well-being Risks among Foreign- born Latinos, U.S.-born Latinos, and Whites? Findings from 50 California Cities
}

\author{
Michelle Johnson-Motoyama ${ }^{\mathrm{a}}$ \\ Michelle Johnson-Motoyama: michellejm@ku.edu \\ aUniversity of Kansas, School of Social Welfare, 1545 Lilac Lane, Lawrence, KS 66045 USA, \\ 785-864-2378
}

\section{Introduction}

In 2010, Latino children represented nearly one-fourth of all children in the United States, or $23 \%$ of all children under the age of 18 (U. S. Census Bureau, 2011). The well-being of Latino children of immigrants (i.e., children with at least one foreign-born parent) is of particular relevance given that they are the fastest-growing segment of the U.S. child population (Passel, 2011), and a group for whom eligibility for many health and social programs is tied to birthplace.

For more than two decades, trends in the physical well-being of Latino children and children of immigrants have been described as a health paradox, a term that typically refers to a pattern of morbidity and/or mortality for a particular group that is at odds with what would be expected given the group's socioeconomic profile (Acevedo-Garcia \& Bates, 2008). In the United States, health paradoxes have been observed for health indicators such as infant low birth weight and infant mortality in epidemiological contrasts between (a) Latinos and whites and (b) foreign-born Latinos and U.S.-born Latinos (Franzini, Ribble, \& Keddie, 2001; Hayes-Bautista, 2002; Jasso, Massey, Rosenzweig, \& Smith, 2004; Palloni \& Arias, 2004; Palloni \& Morenoff, 2001). ${ }^{1}$ The presence of health advantages among Latinos and immigrants, despite socioeconomic disadvantage, has been attributed widely to protective social and cultural dynamics within these groups (e.g., familism, religiosity, salutary health behavior).

This social-cultural explanation is often presented in association with an acculturation hypothesis that predicts the deterioration of health among Latinos over time and across generations in the United States (i.e., health assimilation). Indeed, a small but growing body of longitudinal research suggests that when compared to U.S.-born Latinos and whites, the

(C) 2013 Elsevier Ltd. All rights reserved.

Publisher's Disclaimer: This is a PDF file of an unedited manuscript that has been accepted for publication. As a service to our customers we are providing this early version of the manuscript. The manuscript will undergo copyediting, typesetting, and review of the resulting proof before it is published in its final citable form. Please note that during the production process errorsmaybe discovered which could affect the content, and all legal disclaimers that apply to the journal pertain.

${ }^{1}$ Note that among Latinos, the presence of paradoxes varies by health condition and nationality subgroup (Acevedo-Garcia \& Bates, 2008). 
initial advantages in health observed among infants of immigrant mothers erodes into childhood (Schmeer, 2012) with variation observed depending on the health condition under study (Hamilton, Cardoso, Hummer, \& Padilla, 2011). Declines in the physical health of Latino children of immigrants have been attributed partly to the multiple challenges that immigrant caregivers face in addressing their children's basic needs such as economic hardship (Lopez \& Velasco, 2007; Schmeer, 2012), hunger and food insecurity (Capps, Horowitz, Fortuny, Bronte-Tinkew, \& Zaslow, 2009; Chilton et al., 2009; Kalil \& Chen, 2008; Kersey, Geppert, \& Cutts, 2007; Nord, 2009), and limited access to health care (Blewett, Johnson, \& Mach, 2010; Flores et al., 2002; Perreira \& Ornelas, 2011).

Such challenges are compounded by policies and practices at the federal level and in many states and localities that restrict the access of undocumented individuals to health and social assistance and typically require waiting periods for legal permanent residents.

Approximately $82 \%$ of children of immigrants are U.S. citizens (Passel \& Cohn, 2011) and are therefore eligible to apply for most programs. However, research suggests that policies that negatively impact immigrant caregivers typically have downward effects on citizen children's participation in public programs (Fix \& Zimmerman, 2001; Seiber, 2013).

In many families, problems such as food insecurity, lack of access to medical care, and inadequate supervision are not intentional. Rather, these families care deeply for their children and are trying their best to provide for their children's basic needs with extremely limited resources. However, when chronic, a caregiver's inability to meet a child's basic needs represents a risk for poor child health and for physical neglect, particularly in the context of concerns such as parental substance abuse, domestic violence, and poor mental health.

Belsky's (1993) developmental-ecological framework suggests that physical neglect is produced in the context of caregiver and child characteristics, parent-child interactions, social support, and the broader societal-cultural context (e.g., societal and cultural values embodied in norms, laws, and social policies). Although child protection policies typically focus on caregiver behavior, a caregiver's ability to provide for a child's well-being is informed by multiple factors and processes occurring within this developmental-ecological context. Of these, poverty is recognized as one of the most important correlates (JonsonReid, Drake, \& Zhou, 2012; Sedlak et al., 2010; Slack, Holl, McDaniel, Yoo \& Bolger, 2004).

Given the health paradoxes that have been observed among Latinos of low-income and immigrants in the context of maternal and infant health, researchers have become increasingly interested in patterns that suggest similar paradoxes among children who come to the attention of the U.S. child welfare system. Though findings from national data suggest little difference in the incidence of child maltreatment among Latino children when compared to white children (Sedlak et al., 2010), aggregate data masks a great deal of local variation in state and county estimates of disproportionality and disparities among Latinos in referral, substantiation, and foster care placement when compared to other racial/ethnic groups where both overrepresentation and underrepresentation of Latinos has been observed (Ards et al., 2003; Church et al., 2005; Dettlaff et al., 2011; Needell et al., 2012). However, 
few of these studies have taken socioeconomic position or maternal nativity into account to inform observed differences, primarily because of the limitations inherent to child welfare administrative data.

Recent studies grounded in population-level linkages of child welfare and vital statistics data in California have included these elements and revealed disparities in child protective services involvement that are consistent with the Latino health paradox (Putnam-Hornstein \& Needell, 2011; Putnam-Hornstein, Needell, King, \& Johnson-Motoyama, 2013). For example, when taking household income and maternal nativity into consideration, poor infants of U.S.-born Latino mothers have been found to be at lower risk for referral, substantiation, and foster care entry when compared to those of white mothers, with infants of immigrant Latino mothers at lowest risk for these events among the three groups (Putnam-Hornstein et al., 2013). To date, however, no population-based studies have examined how the distribution of risks to child well-being among Latinos and immigrants comport with the paradoxes that have been observed for infant health and child protective services involvement. Generally speaking, population-based estimates of child neglect risk in the United States have been limited (Straus, Hamby, Finkelhor, Moore \& Runyan, 1998; Theodore, Runyan, \& Chang, 2007), and studies have yet to examine trends within the Latino population by relevant subgroup.

This study draws upon survey data collected from a population-based sample of caregivers in 50 California cities regarding their parenting practices. Informed by Belsky's (1993) developmental-ecological framework, the survey incorporated known covariates of child neglect at the child, caregiver, and social support levels. This study examines the prevalence and magnitude of risks to child well-being among U.S.-born and immigrant Latino caregivers when compared to whites after adjusting for covariates in socioeconomically similar households to determine whether advantages are present among Latino families, despite socioeconomic disadvantage.

\section{Methods}

\section{Data and Participants}

Data were drawn from a random, general population telephone survey of parenting practices among 3,023 parents and guardians in 50 cities across the state of California (Freisthler \& Gruenewald, 2013). Survey data were collected from March to October 2009. The response rate for the survey was calculated at $47.4 \%$ using standard definitions of the American Association of Public Opinion Research (AAPOR, 2004). Data for the current analysis include responses from 2,259 participants who reported race/ethnicity, nativity, and had complete data for the variables under study (88\%). Participants included 1,625 U.S.-born whites (72.0\%), 351 U.S.-born Latinos (15.5\%), and 283 foreign-born Latino (12.5\%) respondents.

\section{Survey Design}

Cities selected for the survey were chosen based on variation in population and environmental characteristics at the census block group level to maximize validity with 
regard to the geography and ecology of the state (Thompson, 1992). Listed samples of household addresses and telephone numbers from credit card, utility companies, and magazine subscription lists were used as the basis for telephone sampling, an approach reported to be unbiased relative to random digit dialing techniques (Brick et al., 1995; Tucker et al., 2002). A pre-notification letter written in English and Spanish was sent to potential respondents to increase the response rate to the survey.

Upon reaching a residence by telephone, the interviewer asked to speak to an adult of at least 18 years of age. A household was considered eligible for inclusion in the study if it contained at least one child 12 years of age or younger that resided in the home at least $50 \%$ of the time. When more than one eligible respondent resided in the household (i.e., two parents), a random selection procedure was employed to invite a single respondent to participate in the survey. The respondent's language preference was assessed by the interviewer at the start of the call (English or Spanish). If the interviewer was not bilingual, the interviewer would attempt to schedule a day/time for the interview or note it on the log so that subsequent attempts would be made in the respondent's preferred language. Verbal informed consent for the interview was obtained in the language of the respondent's preference. When the respondent was a parent or guardian of more than one child 12 years of age or younger, the respondent was instructed to answer questions for an eligible child with the most recent birthday (called the focal child).

The 30-minute survey was administered using computer assisted telephone (CATI) survey procedures in English and Spanish. Items related to child risk were asked via interactive voice response technology (IVR) using a computerized voice menu to elicit responses to sensitive questions. These responses were then encrypted in the data corresponding to the respondent to maintain confidentiality. Respondents received a \$25 check for participation in the survey. Similar to the strategy employed by Brick and Kalton (1996), the study sample was weighted to reflect the population attributes of the cities from which respondents were sampled. Respondents were weighted on gender, race/ethnicity, and household type (i.e., single mother, single father, or two-parent household).

\section{Measures}

Child risks - The prevalence of child risks during the past year was assessed for three measures using Likert-type items from the Multidimensional Neglectful Behavior Scale (MNBS; Kantor, Holt, \& Straus, 2003). Items included:

In the past year, how often have you (a) not had enough food in the house for the child? (b) not been able to take your child to the doctor when he/she was really sick? and (c) left your child places where you weren't sure he/she was really safe?

(Kantor et al., 2003).

Response categories included Never, Sometimes, Often, and Always.

Situations that continue over a long period of time or recur frequently are typically considered chronic in nature and may be more likely to contribute to poor child outcomes when compared to situations that occur infrequently. Therefore, for the purposes of this 
study, child risks were estimated by dichotomizing responses into two categories (a) Never and Sometimes and (b) Often and Always, with the latter category considered indicative of risk to child wellbeing.

Race/ethnicity and nativity-Caregivers were asked to identify their race/ethnicity by providing their first and second choices in response to the question, "Which of these groups best describes your family of origin?" Response categories included: (a) Black or African American; (b) White or Caucasian; (c) Hispanic (including Latino, Mexican, MexicanAmerican, Chicano, other Spanish); (d) Asian or Asian-American, Southeast Asian (including Vietnamese, Hmong, Mien, Lai, Thai); and (e) other. Non-Hispanic white participants were coded as White, and participants who selected Hispanic as a first or second choice were coded as Latino.

Nativity was assessed by asking caregivers "Were you born in the United States or elsewhere?" Race/ethnicity and nativity variables were used to create three mutually exclusive groups: U.S.-born whites (i.e., white), U.S.-born Latinos, and foreign-born Latinos.

Caregiver sociodemographics-Data were collected regarding caregiver gender (male/ female), age in years on the respondent's last birthday, marital status (married or cohabitating, i.e., living with someone in a marriage-like relationship/other), total number of children 18 years of age or under living in the household, level of education (less than high school/high school graduate or GED/some type of higher education), and city of residence. Caregivers were asked to provide their total pre-tax household income for 2008 by selecting from categories ranging from less than $\$ 10,000$ to more than $\$ 150,000$.

Child demographics-Caregivers were asked to provide the gender (male/female) and age in years (birth to 12) of the focal child on their last birthday.

Caregiver depression/anxiety-Respondents were asked to report on past month symptoms of depression and anxiety using items from the Primary Care Evaluation of Mental Disorders (PRIME-MD) tool (Spitzer, Kroenke, Williams, \& PHQ Study Group, 1999). This instrument included two items about depressive symptoms (bothered a lot by little interest or pleasure in doing things; bothered a lot by feeling down, depressed, or hopeless) and three items on symptoms of anxiety (bothered a lot by nerves, or feeling anxious or on edge; bothered a lot by worrying about a lot of different things; suddenly feeling fear or panic). Internal consistency for the PRIME-MD tool in this study was .65 for depression and .61 for anxiety, which was considered acceptable for the study.

Drinking patterns-Drinking patterns were measured using a graduated frequency approach that provides model-based estimates of dimensions of drinking patterns using a mathematical model described by Gruenewald et al. (1996, 2003). Respondents were asked to report the frequencies with which they drank alcohol in the past four weeks. Respondents who had not used alcohol in the past four weeks were asked the same questions over the past year. Categories included abstainer (never drank alcohol)/ex-drinker (did not drink alcohol in the past year, but drank alcohol during his/her lifetime); moderate drinker (drank either 
in the past month or past year but never more than 1-2 drinks per occasion; drank 3-4 drinks at least once during past month but never drank more than 4 drinks); and heavy drinker (drank 5 or more drinks once a month or less; drank 5 or more drinks 2-3 days a month or 1-2 days per week; drank 5 or more drinks 3-5 days per week or daily).

Caregiver impulsivity-The Dickman Dysfunctional Impulsivity Scale (Dickman, 1990) was used to measure respondent impulsivity. Dysfunctional impulsivity, defined as acting rapidly and inaccurately (e.g., I often get into trouble because I don't think before I act), was measured using seven dichotomous items (yes or no), which were summed after reverse coding items, where appropriate. Higher scores on the scale indicate higher levels of impulsivity. Internal consistency was .73 in this study.

Social support and networks-Three subscales from the Interpersonal Support Evaluation List (ISEL; Cohen, Mermelstein, Kamarck, \& Hoberman, 1985) were used to measure perceived social support: tangible support (e.g., If I had to go out of town for a few weeks, it would be difficult to find someone who would look after my house or apartment); emotional support (e.g., I feel that there is no one I can share my most private worries and fears with), and belonging (e.g., If I wanted to have lunch with someone, I could easily find someone to join me). Each subscale contained four items with four response categories including definitely false, probably false, probably true, and definitely true, producing a range from 0 to 12. Internal consistency for the ISEL ranges from . $71-.92$ with a test-retest reliability of $.71-.82$ (Cohen et al., 1985). The square root of the summed measure was used in regression analyses to approximate a normal distribution.

Respondents were also asked to provide an estimate of their social network size for the three types of social support by enumerating the number of friends or family members that (a) provide them with material things to help with their children; (b) talk through problems with or share concerns; and (c) do recreational things with them. Responses were summed and averaged to compute an estimate of total social network size.

\section{Analysis}

Estimates of the past year prevalence of each category of child risk were generated for the full sample and each caregiver race/ethnicity and nativity group using available survey weights (Table 1). Table 2 presents the weighted distribution of covariates for the full sample stratified by caregiver race/ethnicity and nativity. Adjusted Wald tests were used to test null hypotheses of statistical equivalence for all proportions and means.

Crude and adjusted logistic regression models were used to generate odds ratios and $95 \%$ confidence intervals to compare the relative odds of each child risk given caregiver race/ ethnicity and nativity in the full sample, before and after adjusting for covariates (Table 3). All adjusted models included caregiver sociodemographics (race/ethnicity and nativity, gender, age, marital status, total number of children in the household, household income, education), child demographics (gender and age), and caregiver characteristics (anxiety/ depression, drinking pattern, impulsivity, social network size, and perceived social support). 
Table 4 presents the adjusted logistic regression models stratified by household income to compare the odds of each child risk given caregiver race/nativity in socioeconomically similar households. As participants were asked to report their 2008 income in ranges rather than specific dollar amounts, an income threshold of less than $\$ 40,000$ was selected to represent lower income households given that it encompassed eligibility for most public assistance and nutrition programs in California in 2008 (including CalWORKS; the Special Supplemental Nutrition Program for Women, Infants, and Children; California's Child Nutrition Programs; and CalFresh, California's food stamp program).

Regression models were adjusted for clustering by city to account for the correlation of responses in cities with multiple participants. Clustering was selected over the use of weighted analyses given standard errors that were slightly smaller (i.e., less robust) in the weighted analysis when compared to the clustered analyses. Statistical analyses were conducted using StataSE Version 11. The overall logistic regression models presented were statistically significant at the $p<.000$ level.

\section{Findings}

\section{Prevalence of Child Risks}

In the full sample, past year prevalence was highest for caregiver inability to take a sick child to the doctor $(6.4 \%)$, followed by insufficient food for the child (4.5\%) and caregiver report of leaving a child in a questionably safe place (3.1\%; Table 1). Past year prevalence of each category of risk was significantly higher among foreign-born Latino caregivers when compared to other groups: $20.9 \%$ reported inability to take a child to the doctor, $16.1 \%$ reported insufficient food, and $10.3 \%$ reported leaving their child in a place of questionable safety. U.S.-born Latino caregivers (6.7\%) were significantly more likely to report inability to take a sick child to the doctor when compared to their white counterparts $(3.0 \%)$.

\section{Sample Characteristics}

Full sample-Table 2 presents the distribution of study covariates for the full sample ( $n=$ 2,259). Over half of respondents were female (51.9\%). More than three-quarters of respondents were married or living with a partner (78.7\%) with an average of 2.2 children in the household. Caregiver age ranged from 18 to 75 years, with a mean of 39.4 years. More than three-quarters of respondents reported gross household incomes above $\$ 40,000$ in 2008 $(76.1 \%)$ and enrollment in or completion of some type of higher education $(89.7 \%)$. Approximately half of focal children were female (48.4\%), and the majority were more than 5 years old $(62.2 \%)$. Caregivers reported one symptom of depression or anxiety on average $(M=1.01)$. With regard to alcohol use, $41.1 \%$ of caregivers reported moderate drinking, $33.4 \%$ reported heavy drinking, and $25.4 \%$ reported abstaining from drinking or being an ex-drinker. On average, caregivers reported a perceived social support score of 11.0 and a social network size of 11.3 members.

Race/ethnicity and nativity subgroups-Significant variation was observed in the distribution of covariates after stratifying the sample by caregiver race/nativity. Foreign- 
born Latino respondents were more often female (58.8\%) with the largest number children in the household $(M=2.5)$ when compared to other groups. Among the three groups, foreign-born Latino caregivers reported the lowest household incomes and levels of education, the smallest social networks ( 7.3 members on average), and scored lowest on perceived social support.

However, these caregivers were the most likely to report abstaining from alcohol use $(46.5 \%)$ with endorsements of depression/anxiety symptoms that did not differ significantly from whites. By contrast, U.S.-born Latinos were significantly more likely to endorse symptoms of depression or anxiety when compared to whites and to report heavy drinking $(35.9 \%)$ when compared to their white $(34.9 \%)$ and foreign-born counterparts $(23.0 \%)$. Both Latino subgroups were significantly younger than whites and scored higher on Dickman's (1990) measure of impulsivity.

\section{Crude and Adjusted Odds of Child Risks}

Table 3 presents models of crude and adjusted odds ratios for each child risk for the full sample $(n=2,259)$ to determine the contribution of caregiver race/nativity before and after adjustment for covariates.

Crude odds-Notable consistency was observed across each of the crude odds models as similar factors were associated with higher odds for each child risk: caregiver race/ethnicity and nativity (foreign-born Latinos when compared to whites), low household income (< $\$ 40 \mathrm{~K}$ when compared to $\$ 40 \mathrm{~K}+$ ), lower education levels (less than high school and high school/GED completion when compared to higher education), older child age (5 years+ when compared to children $<5$ years), unit increases in caregiver impulsivity, smaller social network sizes (0-3 members and 4-6 members when compared to 12 or more members), and increases in perceived social support.

Adjusted odds-Models were fully adjusted to compare the relative odds of each child risk given caregiver race/ethnicity after accounting for covariates. Across each model, the odds ratios were attenuated but still significantly higher for foreign-born Latino caregivers when compared to white caregivers, and for children five or more years of age when compared to their younger counterparts. With regard to chronically insufficient food and chronic inability to take the child to the doctor, lower household income $(<\$ 40 \mathrm{~K}$ when compared to $\$ 40 \mathrm{~K}+$ ), lower educational levels (less than high school and high school/GED completion when compared to higher education), and caregiver impulsivity were associated with higher odds. Small network size (0-3 members when compared to 12 or more) was associated with higher odds of chronically leaving a child in a questionably safe place (OR 3.51).

\section{Adjusted Models of Child Risks Stratified by Household Income}

To examine child risks among U.S.-born and foreign-born Latino caregivers when compared to whites of similar socioeconomic status, Table 4 presents adjusted odds ratios for the three risks stratified by household income. After adjusting for covariates, notable differences were 
observed in the odds for each child risk given caregiver race/ethnicity and nativity, and these odds varied by household income. These findings are expressed graphically in Figure 1.

Households with incomes $<\$ 40 \mathrm{~K}-$ For foreign-born Latinos, the odds of insufficient food for the child were 12 times as large as the odds for white caregivers $(O R=11.97)$; the odds of inability to take the child to the doctor and chronically leaving a child in a questionably safe place were nearly eight times as large $(O R=7.92$ and $O R=7.93$, respectively). For U.S.-born Latino caregivers, the odds of inability to take the child to the doctor were 4.71 times as large as the odds for white caregivers. Notably, children who were more than five years of age in these lower income households had significantly greater odds for each of the child risks examined when compared to their younger counterparts.

Households with incomes \$40K or higher-In households with greater resources, the odds for each child risk were attenuated or non-significant for foreign-born and U.S.-born Latino caregivers when compared to the odds for white caregivers. Despite this, the odds of insufficient food for the child were still 2.70 times as large for foreign-born Latinos when compared to white caregivers; the odds of chronically leaving a child in a questionably safe place were 3.37 times as large.

\section{Discussion}

Past research has identified health paradoxes in infant health and child welfare services involvement, whereby Latinos and immigrants tend to demonstrate better outcomes with regard to morbidity and mortality and decreased risk for child welfare involvement when compared to whites of similar socioeconomic position. This study demonstrates the significant challenges that immigrant caregivers in lower income households face in meeting their children's basic needs for food, medical care, and safe supervision. Even in households with greater resources, immigrant caregivers were significantly more likely to report difficulty in providing food and safe supervision on a regular basis when compared to their white counterparts. These findings suggest that race/ethnicity and parental nativity embody a number of unmeasured factors that influence child well-being at similar levels of household income despite adjustment for several known covariates of child neglect. For example, differential access to safety net programs may exacerbate a foreign-born parent's ability to provide for a child's basic needs, even when their income level is similar to that of a white parent. Additional research is necessary to determine the ways in which such factors operate to influence child well-being, and at what threshold income is able to offset the risks observed within this population.

In contrast to the paradoxical trends observed for infant health and child protective services involvement, these findings are consistent with national household studies that have demonstrated a higher incidence of food insecurity among ethnic minority households and households in poverty when compared to their white and non-poverty counterparts (Nord et al., 2010). The results also comport with studies that demonstrate the vulnerability of children of immigrants to food insecurity when compared to children of U.S.-born parents (Chilton et al., 2009). Moreover, the findings are consistent with studies that have found Latino children to be uninsured more often than other racial/ethnic groups, less likely to use 
health services, and more likely to experience barriers in accessing health care (Flores et al., 2002). Such trends tend to be amplified among children of immigrants, who as a group are less likely to have health insurance and regular access to health care services when compared to children of U.S.-born parents (Perreira \& Ornelas, 2011). The findings of elevated odds for questionably safe supervision among immigrant caregivers when compared to white caregivers in both household income groupings signal the need for further research to better determine the nature of care arrangements, and parents' concerns for safety.

Despite observed risks, immigrant parents in this study were significantly less likely than U.S.-born Latino parents to report heavy alcohol use. These findings are consistent with a large body of research demonstrating salutary health behavior among immigrants in the general population (see Acevedo-Garcia \& Bates, 2007, for a review) and child welfare involved populations (Dettlaff \& Johnson, 2011; Johnson-Motoyama, Dettlaff, \& Finno, 2012). More research is necessary to determine if such protective factors help to explain the paradoxical trends in child protective services involvement that have been observed among infants of foreign-born mothers in California when compared to their U.S.-born and white counterparts given the substantial role of substance use in child maltreatment dynamics. Notably, past research evincing paradoxical relationships among immigrant involvement in the child protective service system has focused on children during the first five years of life (Putnam-Hornstein \& Needell, 2011; Putnam-Hornstein et al., 2013). These paradoxes may also stem from potential underreporting of child maltreatment among young children of immigrants as a function of differential contact with health, social service, and formal child care providers (Flores et al., 2002; Karoly \& Gonzalez, 2011) or any number of unobserved characteristics related to local child welfare policies and practices with immigrant families (Ayón, 2009). The current study highlights inordinate well-being risks among children five years of age and older, particularly among children in lower income households. Therefore, additional research is needed to explain how such risks may fluctuate over the course of a child's development, and how these risks relate to child health outcomes and child protective service involvement over time, ideally through prospective longitudinal studies.

\section{Limitations}

The current study addresses an important gap in the literature by presenting populationbased, self-reported data regarding risks to child well-being using a unique dataset that included parental race/ethnicity and nativity information. Despite its contribution, several study limitations exist, and the findings presented here should be interpreted with caution. The first caveat concerns the generalizability of study findings due to telephone nonresponse. A growing literature has been chronicling the continuing decline in response rates for telephone surveys over the past few decades (Kempf \& Remington, 2007), a trend reflected in the study's 47\% response rate. For example, Curtin, Presser, and Singer (2005) reported that response rates for the University of Michigan's Survey of Consumer Attitudes declined from $72 \%$ in 1979 to a low of $48 \%$ in 2003. At the Pew Research Center, the response rate of a typical telephone survey was 36\% in 1997 and is $9 \%$ today (Kohut, Keeter, Doherty, Dimock \& Christian, 2012). One approach to dealing with the lack of representativeness stemming from nonresponse was to weight study sample segments to 
reflect the greater population attributes of the sampled cities (Brick \& Kalton, 1996). The proportion of adult Latinos living in the cities sampled averaged $21.2 \%$ with a range of $4.35 \%$ to $65 \%$. In this sense, Latinos in this study were overrepresented at $28 \%$ but underrepresented when compared to California's general population of $38 \%$. Moreover, foreign-born respondents were notably underrepresented at the aggregate city and state levels; younger and less educated respondents were underrepresented at the state level (U.S. Census, 2011).

Several factors may explain telephone non-response as well as the underrepresentation of particular groups in this study. First, participants in this study were limited to individuals with working landline telephones. Past research suggests individuals without landline telephones are more likely to be non-White, and less educated, and more likely to report worse self-rated health than those with a phone (Kempf \& Remington, 2007). Renters are also more likely to be without a phone than those who own their own home, as are those who are unemployed (Kempf \& Remington, 2007). Individuals with cell phones only, who would have been excluded from this study, tend to be young (18 to 30) and wealthy renters who tend to live alone or with roommates, or poor, non-whites who have no landline for economic reasons (Kempf \& Remington, 2007). Finally, interactive voice response technology was used to reduce bias associated with the underreporting of behaviors that might be considered inappropriate. However, it is still possible that social desirability would lead some parents to underreport the child risks under study. Therefore, biases associated with telephone non-coverage and social desirability would tend to underestimate the true prevalence of risks within the general population under study as well as the prevalence of risks among younger parents, parents lower levels of education, and foreign-born parents, particularly those in migrant families.

With regard to measurement limitations, single items were used to approximate child risks. Items were selected to reflect subtypes of physical neglect (failure to provide) and supervisory neglect that appear within the child protective services system. Future research should include multidimensional measures that provide a more detailed understanding of the phenomena under study (e.g., severity, duration) as well as the practices that participants engage in to mitigate such conditions. As in Theodore et al.'s (2007) study, there are other basic needs that were not addressed by the current survey such as parental ability to meet a child's needs for shelter, education, and nurturance (Dubowitz et al., 2000), which might be included in future studies. Another limitation stems from the cross-sectional nature of the data, which limited the ability to anchor variables and relationships temporally.

Finally, past research has noted the importance of factors such as English language ability, citizenship status, documentation, and total number of years in the U.S. to food insecurity (Capps et al., 2009) and health care access and utilization (Perreira \& Ornelas, 2011). Future research should seek to incorporate these variables along with national and territorial origin, which embody important differences in immigration experiences, benefit eligibility, and cultural beliefs and practices among Latino subgroups. Future studies should also include related data for children given the linkage of child citizenship to child eligibility for public programs. 


\section{Implications for Practice and Policy}

The detrimental effects of insufficient food, lack of medical care, and unsafe supervision on the physical, cognitive, and emotional development of children have been well-established. Findings from this sample, which appear to be an older and more highly educated group of adults when compared to averages for the state of California, suggest that children of immigrants face inordinate risks to their well-being that are likely amplified within less established families of lower socioeconomic position. By 2050, children of immigrants are projected to comprise one-third of U.S. children (Passel, 2011). Given rapid growth in this population, and the fact that poor childhood health contributes to lower socioeconomic status in adulthood, it is imperative for policymakers to work toward solutions to the problems signaled by these findings to address growing disparities in the health and wellbeing of Latino children. In the current political context, targeted investments in children of immigrants are likely to be met with considerable opposition in many political jurisdictions. Nonetheless, steps can be taken to enhance the well-being of children of immigrants, the vast majority of which are citizens (Passel \& Cohn, 2011). Studies suggest that disadvantaged youth often benefit disproportionately from universal social programs; therefore, investments in children of immigrants can be targeted within universal programs focused on health, nutrition, and child care, with goals designed to increase participation rates among children of immigrants (Tienda \& Haskins, 2011). At the community level, organizations have the opportunity to collaborate to better facilitate access and remove barriers to available resources in the context of culturally relevant outreach and services. However, as the Obama Administration continues to work toward comprehensive immigration reform, priority must be given to creating a system through which immigrants, particularly non-citizen parents and non-citizen children, can achieve a recognized legal status that provides opportunities for gainful, non-exploitative employment at living wages to lift their families out of poverty, thereby mitigating demands for social assistance. In this sense, policy makers and professionals have an unprecedented opportunity to influence the long-term economic prospects of our future generations and the health of our society.

\section{References}

Acevedo-Garcia, D.; Bates, LM. Latino health paradoxes: Empirical evidence, explanations, future research and implications. In: Rodríguez, H.; Sáenz, R.; Menjívar, C., editors. Latinas/os in the United States: Changing the face of America. New York, NY: Springer; 2008. p. 101-113.

American Association for Public Opinion Research. Standard definitions: Final dispositions of case codes and outcome rates for surveys. 2. Ann Arbor, MI: Author; 2004.

Ards SD, Myers SL Jr, Malkis A, Sugrue E, Zhou L. Racial disproportionality in reported and sustained child abuse and neglect: An examination of systematic bias. Children and Youth Services Review. 2003; 25:375-392.

Ayón C. Shorter time-lines, yet higher hurdles: Mexican families' access to child welfare mandated services. Children and Youth Services Review. 2009; 31:609-616.

Belsky J. Etiology of child maltreatment: A developmental- ecological analysis. Psychological Bulletin. 1993; 114:413-434. [PubMed: 8272464]

Blewett LA, Johnson PJ, Mach AL. Immigrant children's access to health care: Differences by global region of birth. Journal of Health Care for the Poor and Underserved. 2010; 21(2 Suppl):13-31. [PubMed: 20453374]

Brick JM, Waksberg J, Kulp D, Starer A. Bias in list-assisted telephone samples. Public Opinion Quarterly. 1995; 59:218-235. 
Brick JM, Kalton G. Handling missing data in survey research. Statistical methods in medical research. 1996; 5:215-38. [PubMed: 8931194]

Capps, R.; Horowitz, A.; Fortuny, K.; Bronte-Tinkew, J.; Zaslow, M. Young children in immigrant families face higher risk of food insecurity. Washington, DC: Child Trends; 2009.

Chilton M, Black MM, Berkowitz C, Casey PH, Cook J, Cutts D, Frank DA. Food insecurity and risk of poor health among US-born children of immigrants. American Journal of Public Health. 2009; 99:556-562. [PubMed: 19106417]

Cohen, S.; Mermelstein, R.; Kamarck, T.; Hoberman, H. Measuring the functional components of social support. In: Sarason, IG.; Sarason, B., editors. Social support: Theory, research and applications. The Hague, The Netherlands: Martinus Nijhoff; 1985. p. 73-94.

Curtin R, Presser S, Singer E. Changes in telephone survey nonresponse over the past quarter century. Public Opinion Quarterly. 2005; 69:87-98.

Dettlaff AJ, Johnson MA. Child maltreatment dynamics among immigrant and U.S. born Latino children: Findings from the National Survey of Child and Adolescent Well-being (NSCAW). Children Youth Services Review. 2011; 33:936-944.

Dettlaff AJ, Rivaux SL, Baumann DJ, Fluke JD, Rycraft JR, James J. Disentangling substantiation: The influence of race, income, and risk on the substantiation decision in child welfare. Children and Youth Services Review. 2011; 33:1630-1637.

Dickman SJ. Functional \& dysfunctional impulsivity: personality \& cognitive correlates. Journal of Personality and Social Psychology. 1990; 58:95-102. [PubMed: 2308076]

Fix M, Zimmerman W. All under one roof, mixed status families in an era of reform. International Migration Review. 2001; 35(134):397-419.

Flores G, Fuentes-Afflick E, Barbot O, Carter-Pokras O, Claudio L, Lara M, Weitzman M. The health of Latino children: Urgent priorities, unanswered questions, and a research agenda. Journal of the American Medical Association. 2002; 288:82-90. [PubMed: 12090866]

Franzini L, Ribble JC, Keddie AM. Understanding the Hispanic paradox. Ethnicity and Disease. 2001; 11(3):496-518. [PubMed: 11572416]

Freisthler B, Gruenewald PJ. Where the individual meets the ecological: A study of parent drinking patterns, alcohol outlets, and child physical abuse. Alcoholism: Clinical and Experimental Research. 2012:1-8.

Gruenewald PJ, Johnson F, Light J, Lipton R, Saltz R. Understanding college drinking: Assessing dose-response from survey self-reports. Journal of Studies on Alcohol. 2003; 64:500-514. [PubMed: 12921192]

Gruenewald PJ, Mitchell PR, Treno AJ. Drinking and driving: Drinking patterns and drinking problems. Addiction. 1996; 91:1637-1649. [PubMed: 8972922]

Hamilton ER, Cardoso JB, Hummer RA, Padilla YC. Assimilation and emerging health disparities among new generations of US children. Demographic Research. 2011; 25:783-818.

Hayes-Bautista, DE. The Latino health research agenda for the twenty-first century. In: SuárezOrozco, MM.; Páez, M., editors. Latinos remaking America. Berkeley: University of California Press; 2002. p. 215-235.

Jasso, G.; Massey, DS.; Rosenzweig, MR.; Smith, JP. Institute for Fiscal Studies. London, England: Author; 2004. Immigrant health: Selectivity and acculturation.

Johnson-Motoyama M, Dettlaff AJ, Finno M. Parental nativity and the decision to substantiate: Findings from a study of Latino children in the second National Survey of Child and Adolescent Well-being (NSCAW II). Children and Youth Services Review. 2012; 34:2229-2239.

Karoly LA, Gonzalez GC. Early care and education for children in immigrant families. The Future of Children. 2011; 21:71-102. [PubMed: 21465856]

Kempf AM, Remington PL. New challenges for telephone survey research in the twenty-first century. Annual Review of Public Health. 2007; 28:113-126.

Jonson-Reid M, Drake B, Zhou P. Neglect subtypes, race, and poverty: Individual, family, and service characteristics. Child Maltreatment. 2013; 18:30. [PubMed: 23109353]

Kalil A, Chen JH. Mothers' citizenship status and household food insecurity among low-income children of immigrants. New Directions for Child and Adolescent Development. 2008; 121:43-62. [PubMed: 18792952] 
Kantor, GK.; Holt, M.; Straus, MA. The Parent-Report Multidimensional Neglectful Behavior Scale. Durham: Family Research Laboratory, University of New Hampshire; 2003.

Kersey M, Geppert J, Cutts DB. Hunger in young children of Mexican immigrant families. Public Health Nutrition. 2007; 10:390-395. [PubMed: 17362535]

Kohut, A.; Keeter, S.; Doherty, C.; Dimock, M.; Christian, L. Assessing the representativeness of public opinion surveys. Washington, DC: Pew Research Center for the People \& the Press; 2012.

Lopez, MH.; Velasco, G. Childhood poverty among Hispanics sets record, leads nation. Washington, DC: Pew Hispanic Center; 2011.

Mazur RE, Marquis GS, Jensen HH. Diet and food insufficiency among Hispanic youths: Acculturation and socioeconomic factors in the third National Health and Nutrition Examination Survey. American Journal of Clinical Nutrition. 2003; 78:1120-1127. [PubMed: 14668273]

Needell, B.; Webster, D.; Armijo, M.; Lee, S.; Dawson, W.; Magruder, J.; Nuttbrock, A. Child welfare services reports for California. 2012. Retrieved from http://cssr.berkeley.edu/

Nord, M. Economic Information Bulletin No (EIB-56). Washington, DC: U.S. Department of Agriculture; 2009. Food insecurity in households with children: Prevalence, severity, and household characteristics.

Nord, M.; Coleman-Jensen, A.; Andrews, M.; Carlson, S. Household food security in the United States, 2009 (Economic Research Report No. ERR-108). Washington, DC: U.S. Department of Agriculture; 2010.

Palloni A, Arias E. Paradox lost: Explaining the Hispanic adult mortality advantage. Demography. 2004; 41:385-415. [PubMed: 15461007]

Palloni A, Morenoff JD. Interpreting the paradoxical in the Hispanic paradox -Demographic and epidemiologic approaches. Annals of the New York Academy of Sciences. 2001; 954:140-174. [PubMed: 11797855]

Passel JS. Demography of immigrant youth: Past, present, and future. The Future of Children. 2011; 21:19-41. [PubMed: 21465854]

Passel, JS.; Cohn, D. Unauthorized immigrant population: National and state trends, 2010. Washington, DC: Pew Hispanic Center; 2011.

Perreira KM, Ornelas IJ. The physical and psychological well-being of immigrant children. The Future of Children. 2011; 21:195-218. [PubMed: 21465861]

Putnam-Hornstein E, Needell B. Predictors of child protective service contact between birth and age five: An examination of California's 2002 birth cohort. Children and Youth Services Review. 2011; 33:2400-2407.

Putnam-Hornstein E, Needell B, King B, Johnson-Motoyama M. Racial and ethnic disparities: A population-based examination of risk factors for involvement with child protective services. Child Abuse \& Neglect. 2013; 37:33-46. [PubMed: 23317921]

Schmeer KK. Early childhood economic disadvantage and the health of Hispanic children. Social Science \& Medicine. 2012; 75:1523-1530. [PubMed: 22818489]

Sedlak, AJ.; Mettenburg, J.; Basena, M.; Petta, I.; McPherson, K.; Greene, A.; Li, S. Fourth national incidence study of child abuse and neglect (NIS-4): Report to Congress. Washington, DC: U.S. Department of Health and Human Services, Administration for Children and Families; 2010.

Seiber E. Which states enroll their Medicaid-eligible, citizen children with immigrant parents? Health Services Research. 2013; 48(2 Part 1):519-538. [PubMed: 23003669]

Slack KS, Holl JL, McDaniel M, Yoo J, Bolger K. Understanding the risks of child neglect: An exploration of poverty and parenting characteristics. Child Maltreatment. 2004; 9:395-408. [PubMed: 15538038]

Spitzer RL, Kroenke K, Williams JBW. the Patient Health Questionnaire Primary Care Study Group. Validation and utility of a self-report version of PRIME-MD: The PHQ Primary Care Study. JAMA. 1999; 282:1737-1744.10.1001/jama.282.18.1737 [PubMed: 10568646]

Straus MA, Hamby SL, Finkelhor D, Moore DW, Runyan D. Identification of child maltreatment with the Parent-Child Conflict Tactics Scales: Development and psychometric data for a national sample of American parents. Child Abuse and Neglect. 1998; 22:249-270. [PubMed: 9589178]

Theodore A, Runyan D, Chang JJ. Measuring the risk of physical neglect in a population-based sample. Child Maltreatment. 2007; 12:96. [PubMed: 17218651] 
Tienda M, Haskins R. Immigrant children: Introducing the issue. The Future of Children. 2011; 21:318.

Thompson, SK. Sampling. New York, NY: Wiley; 1992.

U. S. Census Bureau. US Census Bureau delivers final state census population totals for legislative redistricting (CB 11-CN.123). 2011 Mar 24. Retrieved from http://www.census.gov 


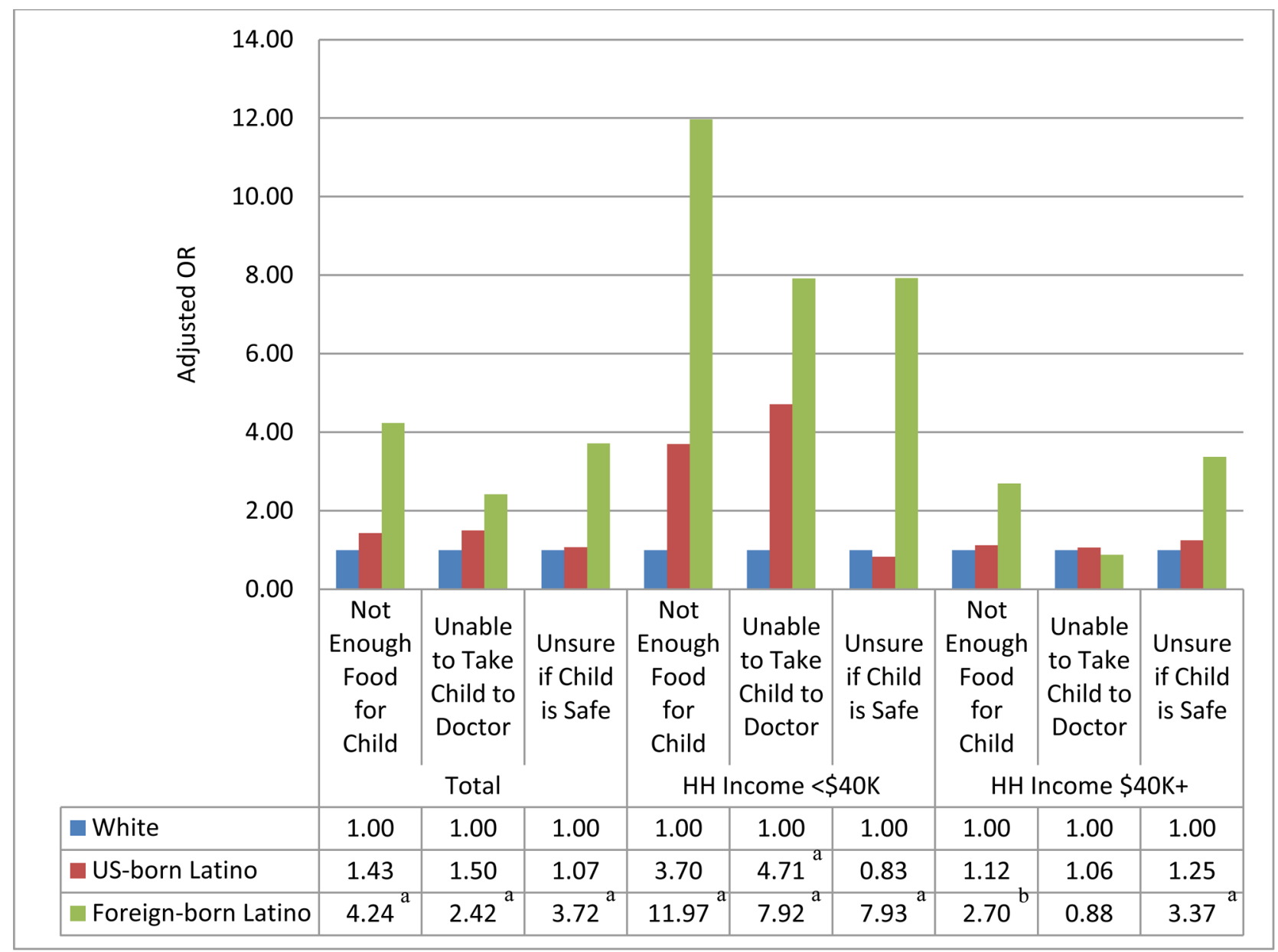

Figure 1.

Adjusted odds ratios for child risks stratified by household income.

Note: Odds ratios (OR) are adjusted for caregiver gender, age, marital status, total number of children in the household, education, depression/anxiety, drinking pattern, impulsivity, social support and child gender and age. Significant odds ratios are presented for foreignborn Latino and U.S. born Latino caregivers when compared to white caregivers $\left({ }^{\mathrm{a}} \mathrm{p}<\right.$. $\left.000 ;{ }^{\mathrm{b}} \mathrm{p}<.05\right)$. 


\section{Table 1}

Weighted past year prevalence of child risks, stratified by race/nativity $(n=2,259)$.

\begin{tabular}{lcccc}
\hline Child Risk & Total $(\boldsymbol{n = 2 , 2 5 9 )}$ & White $(\boldsymbol{n = 1 , 6 2 5})$ & U.S.-born Latino $(\boldsymbol{n = 3 5 1})$ & Foreign-born Latino $(\boldsymbol{n}=283)$ \\
\hline Not enough food for child & $4.5 \%$ & $1.8 \%$ & $4.7 \%$ & $b, c_{16} .1 \%$ \\
Unable to take child to doctor & $6.4 \%$ & $3.0 \%$ & $a_{6.7 \%}$ & $b, c_{2} 0.9 \%$ \\
Unsure if child is safe & $3.2 \%$ & $1.8 \%$ & $2.6 \%$ & $b, c_{10}, 3 \%$ \\
\hline
\end{tabular}

Note. Statistically significant difference $(\mathrm{p}<.05)$ between

${ }^{a}$ U.S.-born Latinos and whites,

$b_{\text {foreign-born Latinos and whites, and }}$

$c_{\text {foreign-born Latinos and U.S.-born Latinos. }}$ 
Table 2

Weighted sample characteristics stratified by race/nativity $(n=2,259)$.

\begin{tabular}{|c|c|c|c|c|}
\hline Variable & Total $(n=2259)$ & White (n=1,625) & U.S.-born Latino (n=351) & Foreign-born Latino $(n=283)$ \\
\hline \multicolumn{5}{|l|}{ Demographics } \\
\hline Female Caregiver 51.9\% & $50.5 \%$ & $51.8 \%$ & $b_{58.8 \%}$ & \\
\hline Caregiver Age (mean) & 39.4(.33) & $40.6(.30)$ & $a_{36.7(.69)}$ & $b_{37.7(.52)}$ \\
\hline $18-32$ years & $19.3 \%$ & $13.1 \%$ & $a_{35.3 \%}$ & $b, c_{24.3 \%}$ \\
\hline $33-40$ years & $35.8 \%$ & $36.3 \%$ & $a_{28.7 \%}$ & $c_{43.4 \%}$ \\
\hline $41-48$ years & $33.5 \%$ & $37.2 \%$ & $a_{28.2 \%}$ & $b_{24.7 \%}$ \\
\hline $49-75$ years & $11.2 \%$ & $13.2 \%$ & $a_{7.7 \%}$ & $b_{7.5 \%}$ \\
\hline Married or Cohabitating & $78.7 \%$ & $79.6 \%$ & $73.6 \%$ & $81.7 \%$ \\
\hline Total \# Children (mean) & $2.2(.03)$ & $2.1(.02)$ & $2.3(.07)$ & $b, c_{2.5(.07)}$ \\
\hline \multicolumn{5}{|l|}{ Household Income } \\
\hline$<\$ 20,000$ & $9.0 \%$ & $4.4 \%$ & $a_{12.9 \%}$ & $b, c_{24.5 \%}$ \\
\hline$\$ 20,001-\$ 40,000$ & $14.9 \%$ & $8.6 \%$ & $a_{20.4 \%}$ & $b, c_{35.0 \%}$ \\
\hline$\$ 40,001-\$ 60,000$ & $13.6 \%$ & $11.8 \%$ & $14.9 \%$ & $b_{19.7 \%}$ \\
\hline$\$ 60,001-\$ 80,000$ & $15.7 \%$ & $17.0 \%$ & $18.5 \%$ & $b, c_{6.0 \%}$ \\
\hline$\$ 80,001-\$ 100,000$ & $14.0 \%$ & $16.6 \%$ & $a_{11.0 \%}$ & $b_{7.0 \%}$ \\
\hline$\$ 100,001+$ & $32.8 \%$ & $42.0 \%$ & $a_{22.5 \%}$ & $b, c_{7.8 \%}$ \\
\hline \multicolumn{5}{|l|}{ Caregiver Education } \\
\hline Less than high school & $6.3 \%$ & $1.3 \%$ & $a_{6.2 \%}$ & $b, c 29.2 \%$ \\
\hline High school & $14.2 \%$ & $9.0 \%$ & $a_{22.7 \%}$ & $b_{25.2 \%}$ \\
\hline Higher education & $79.5 \%$ & $89.7 \%$ & $a_{71.1 \%}$ & $b, c 45.6 \%$ \\
\hline Female Child & $48.4 \%$ & $47.6 \%$ & $53.7 \%$ & $44.9 \%$ \\
\hline \multicolumn{5}{|l|}{ Child's Age } \\
\hline$<=5$ years & $37.8 \%$ & $35.0 \%$ & $a_{45.0 \%}$ & $39.4 \%$ \\
\hline $5+$ years & $62.2 \%$ & $64.9 \%$ & $55.0 \%$ & $60.6 \%$ \\
\hline \multicolumn{5}{|l|}{ Caregiver Characteristics } \\
\hline Depression/anxiety (mean) & $1.01(.04)$ & $.93(.04)$ & $a_{1.29(.11)}$ & $1.01(.11)$ \\
\hline \multicolumn{5}{|l|}{ Drinking Pattern } \\
\hline Abstainer/ Ex-drinker & $25.4 \%$ & $20.8 \%$ & $25.2 \%$ & $b, c_{46.5 \%}$ \\
\hline Moderate drinker & $41.1 \%$ & $44.3 \%$ & $38.9 \%$ & $b_{30.5 \%}$ \\
\hline Heavy drinker & $33.4 \%$ & $34.9 \%$ & $a_{35.9 \%}$ & $b, c 23.0 \%$ \\
\hline Impulsivity (mean) & $0.8(.04)$ & $0.6(.04)$ & $a_{0.9(.09)}$ & $b_{1.1(.09)}$ \\
\hline Social network size (mean) & $11.3(.30)$ & $12.1(.37)$ & $11.5(.76)$ & $b, c_{7.3(.37)}$ \\
\hline Perceived social support (mean) & $11.0(.06)$ & $11.2(.05)$ & $a_{10.8(.15)}$ & $b, c 10.1(.17)$ \\
\hline
\end{tabular}

Note. Statistically significant difference $(\mathrm{p}<.05)$ between

${ }^{a}$ U.S.-born Latinos and whites, 
$b_{\text {foreign-born Latinos and whites, and }}$

${ }^{c}$ foreign-born Latinos and U.S.-born Latinos 


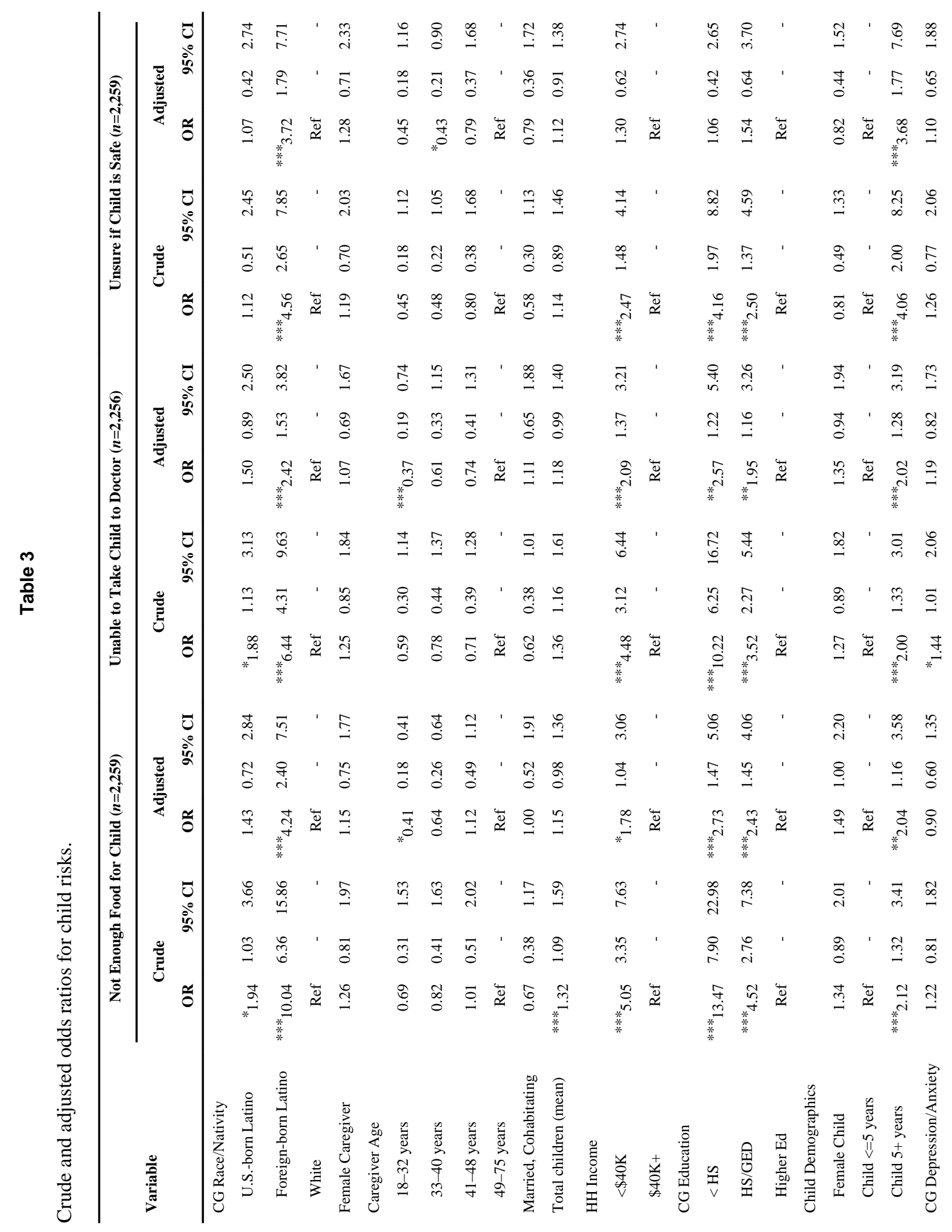




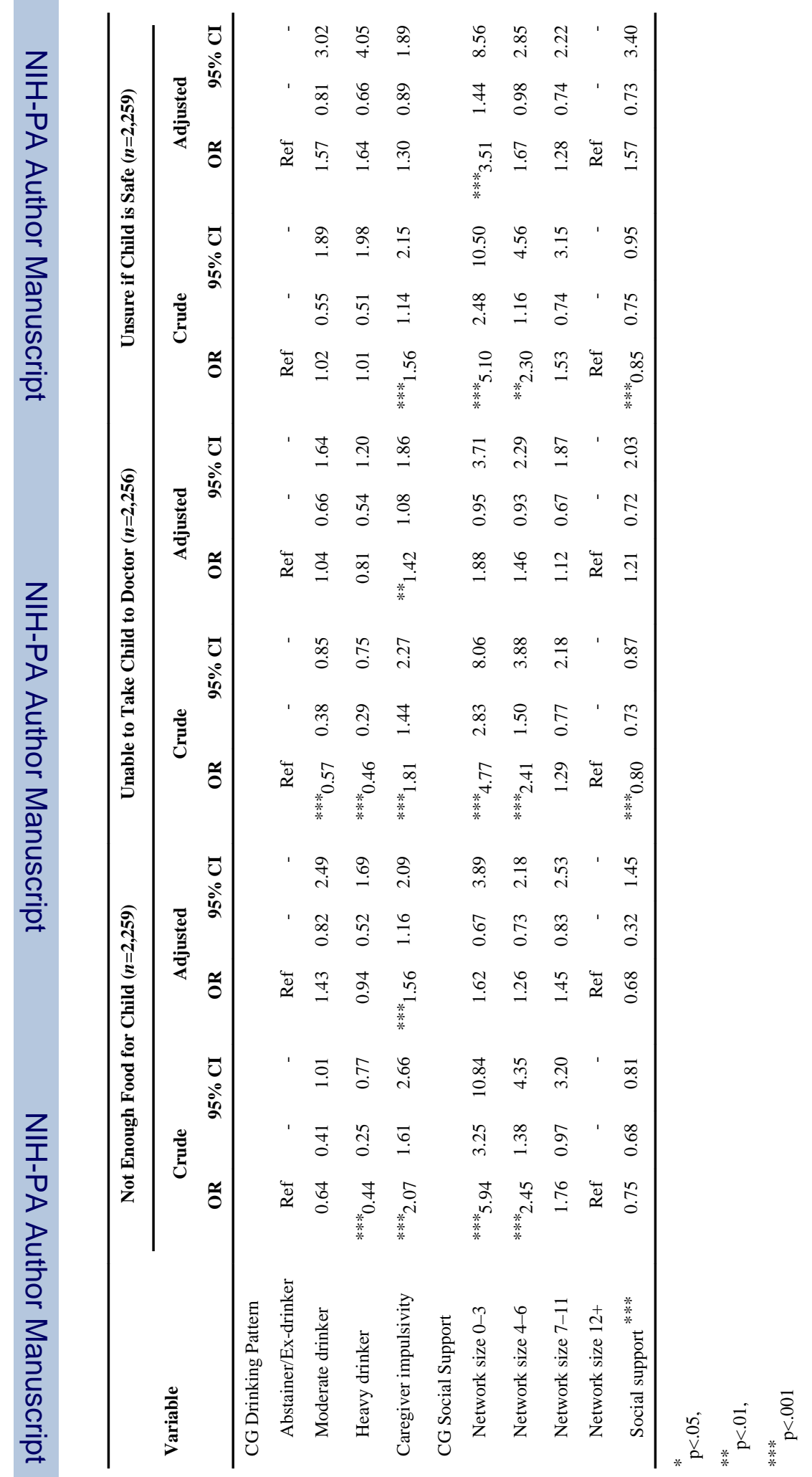




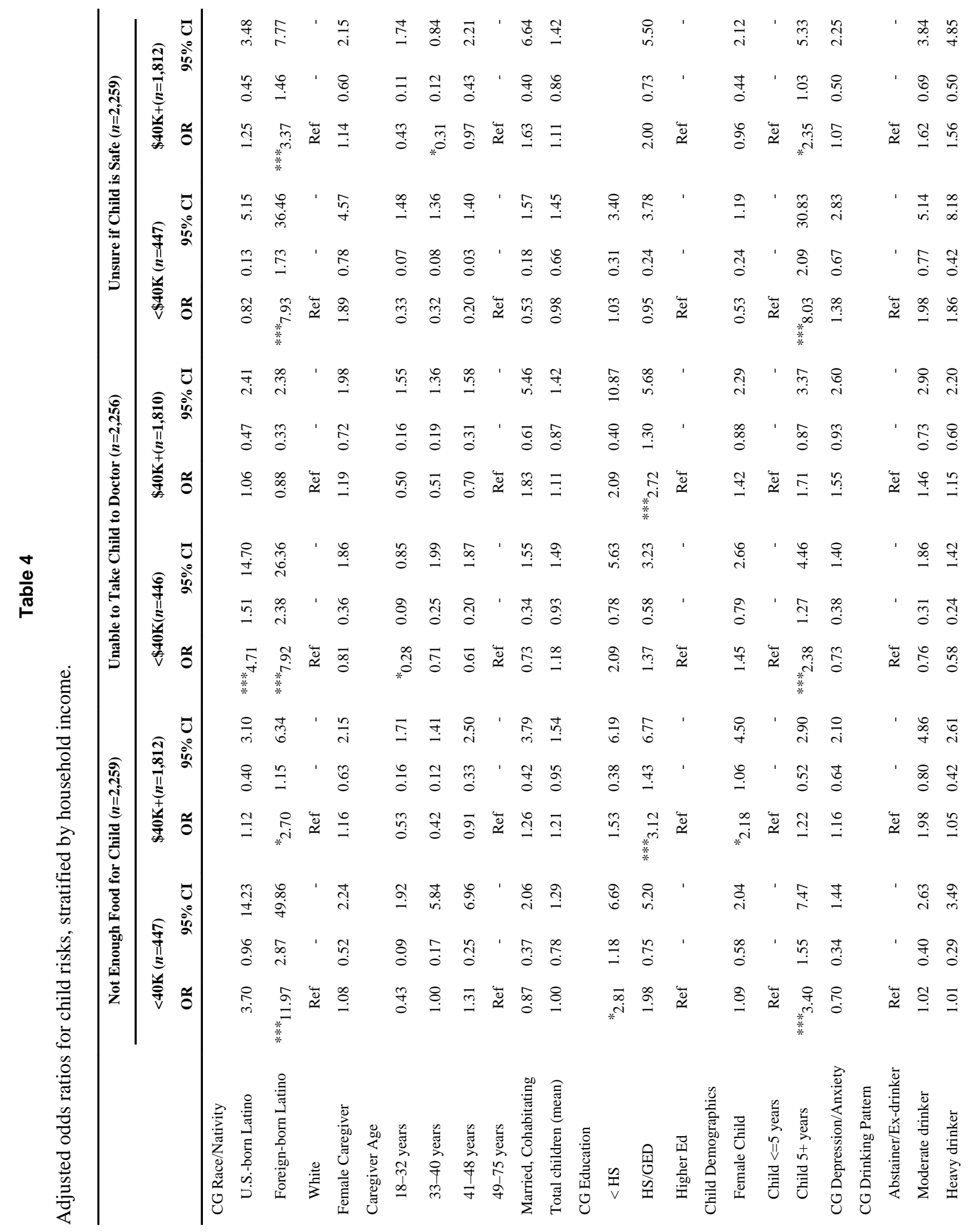




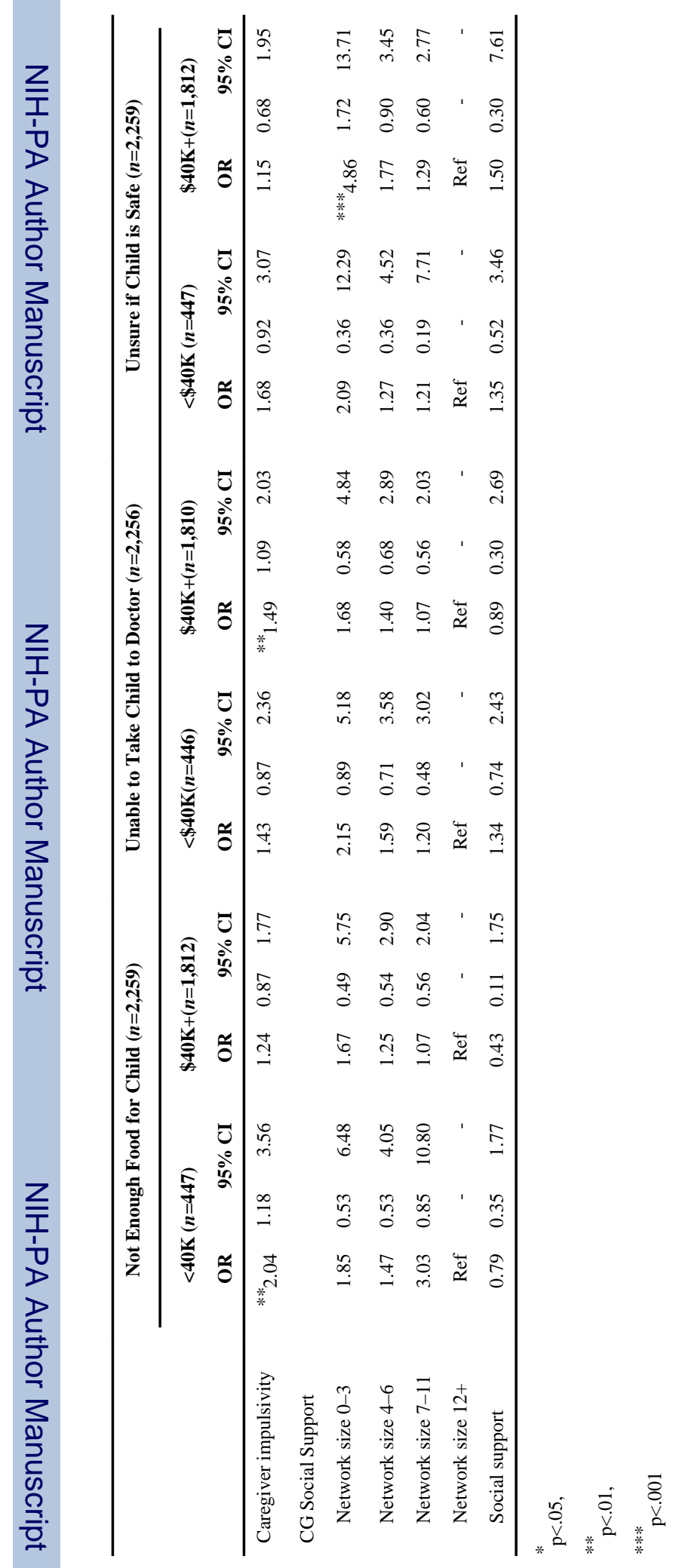

